\title{
PENGARUH PENGGUNAAN CINEMATHERAPY TERHADAP PENINGKATAN MOTIVASI BELAJAR SISWA (Studi Kuasi Eksperimen Terhadap Siswa Kelas XI di SMA Negeri 59 Jakarta)
}

\author{
Aprilia Murdia Ningsih ${ }^{1}$ \\ Dede Rahmat Hidayat ${ }^{2}$ \\ Endang Setiyowati ${ }^{3}$
}

\begin{abstract}
Abstrak
Penelitian ini bertujuan untuk mengetahui pengaruh perlakuan cinematherapy terhadap peningkatan motivasi belajar siswa. Penelitian5 ini dilakukan di SMAN 59 Jakarta pada bulan Juli sampai dengan September 2015. Penelitian ini menggunakan metode kuasi eksperimen dengan bentuk Nonequivalent Control Group Design. Instrumen motivasi memiliki 63 item butir pernyataan yang valid dan memiliki koefisien reliabilitas sebesar 0.940. Berdasarkan hasil pengujian hipotesis dengan menggunakan teknik Mann Whitney U Test, diperoleh nilai Asymp. Sig sebesar 0.012 yang berarti nilai probabilitas lebih kecil dari nilai signifikansi $\alpha 0.05$. Dengan demikian dapat disimpulkan bahwa $\mathrm{H}_{0}$ ditolak dan $\mathrm{H}_{1}$ diterima, yaitu terjadi peningkatan motivasi yang signifikan setelah diberikan cinematherapy. Berdasarkan penelitian yang telah dilakukan, cinematherapy berpengaruh positif terhadap peningkatan motivasi siswa yang memiliki motivasi diri rendah. Cinematherapy dapat diterapkan oleh guru bimbingan dan konseling di sekolah sebagai salah satu alternatif penanganan untuk menangani siswa yang mengalami masalah rendahnya motivasi.
\end{abstract}

Kata Kunci: Cinematherapy, motivasi belajar, remaja

\section{PENDAHULUAN}

Masa remaja adalah masa transisi dalam rentang kehidupan manusia, yang menghubungkan masa kanak-kanak dan dewasa (Hurlock, 1980). Dalam masa transisi tersebut, remaja mengalami banyak perubahan dalam kognitif, fisik, maupun emosi. Terjadinya pergolakan tersebut menimbulkan ketidakmampuan remaja dalam mengendalikan dirinya. Salah satunya adalah kurang atau rendahnya motivasi remaja. Menurut Morgan, motivasi adalah tenaga pendorong atau penarik yang menyebabkan adanya tingkah laku ke arah suatu tujuan tertentu (Morgan, 1986). Dalam konteks pendidikan di sekolah, keinginan untuk meraih prestasi tampak ketika siswa berusaha keras mempelajari subjek tertentu atau ketika mereka berjuang keras untuk meraih tujuan tugas tertentu dalam belajar (Arends, 2008). Banyak hal yang bisa mempengaruhinya, sehingga membuat remaja bingung dan tidak tahu apa yang harus dilakukannya. Selain itu, adanya masalah lain yang mereka hadapi sering menimbulkan perilaku tidak bertanggung jawab seperti menyontek yang sudah dianggap biasa dan tidak memiliki rasa semangat hidup dalam menjalani kehidupan selanjutnya. Remaja tidak memiliki rencana masa depan dan tujuan dalam hidup.

Berdasarkan pada permasalahan yang muncul, maka perlu adanya bimbingan

\footnotetext{
${ }^{1}$ Mahasiswa Program Studi Bimbingan dan Konseling FIP UNJ, amurdia@yahoo.com

${ }^{2}$ Dosen Program Studi Bimbingan dan Konseling FIP UNJ, d_r_hidayat@yahoo.com

${ }^{3}$ Dosen Program Studi Bimbingan dan Konseling FIP UNJ, esetiyowati63@yahoo.com
} 
dan bentuk bantuan yang dipilih dengan menggunakan teknik cinematherapy. Menurut terapis Film Gary Solomon, cinematherapy adalah penggunaan film yang memiliki efek positif pada seseorang kecuali yang memiliki gangguan psikotik (Demir, 2007). Melalui media film ini, klien dapat menggambarkan lebih mudah terhadap kesedihan, ketenangan dan mampu lebih santai, juga lebih mampu untuk menyampaikan masalahnya, dan menemukan bahwa film mampu memimpin katarsis emosional yang dialami klien, sehingga makna dalam film tersebut dapat tersampaikan dan membantu meningkatkan perkembangan dan wawasan klien serta mengatasi masalah.

Berdasarkan permasalahan yang terjadi di atas, maka rumusan masalah dalam penelitian ini adalah mengenai: "Apakah terdapat Pengaruh Cinematherapy dalam Meningkatkan Motivasi Belajar Siswa SMAN 59 Jakarta?”

\section{KAJIAN TEORETIK TERAPI KELOMPOK THERAPY)}

Rawlins, Williams dan Beck (1993) mengungkapkan terapi kelompok adalah metode pengobatan ketika seseorang ditemui dalam rancangan waktu tertentu dengan tenaga yang memenuhi persyaratan tertentu. (Wahab, 2014). Terapi kelompok adalah terapi psikologi yang dilakukan secara kelompok untuk memberikan stimulasi bagi pasien dengan gangguan interpersonal (Yosep, 2008). Terapi aktivitas kelompok mempunyai tujuan umum dan khusus (Yosep, 2008)

\section{CINEMATHERAPY}

Menurut terapis Film Gary Solomon, cinematherapy adalah penggunaan film yang memiliki efek positif pada seseorang kecuali yang memiliki gangguan psikotik (Demir, 2007). Menurut Wolz, lebih banyak orang merasa lega dengan menonton film-film dari psikoterapi. Wolz mengatakan bahwa film dapat memberikan pelepasan emosional yang sehat. Dia menunjukkan penelitian medis tentang tertawa dan menangis. Tertawa meningkatkan sistem kekebalan tubuh dan mengurangi hormon stres dan menangis melepaskan pemancar neuro yang mengurangi rasa sakit (Demir, 2007).

Ada beberapa manfaat penting dalam menggunakan cinematherapy sebagai alat terapi. Salah satu keuntungan (McGrath, 1989) adalah: (1) Film memberikan alternatif cara untuk menciptakan perubahan dalam cara yang tidak mengancam. (2) Film memberi kesempatan klien untuk aman dalam menilai ide-ide dan perilaku alternatif. Dua poin yang penting adalah saat pemilihan film yang tepat dan mengikuti pedoman cinematherapy. Solomon mengatakan bahwa ide dalam pemilihan film adalah memilih film yang mencerminkan masalah konseli saat ini (Wolz, 2003).

Tahapan cinematherapy ini dikembangkan oleh Michael Lee Powell yang merupakan hasil adaptasi dari Dermer, S. B., \& Hutchings, J. B., yaitu:

1. Tahap Satu: Asesmen

a. Mengidentifikasi permasalahan dan menentukan tujuan dalam terapi.

b. Menilai dan mengetahui konseli dari segi kemampuan, keingintahuan, kematangan, ketertarikan, kepentingan, kegiatan, aktivitas.

c. Menelaah kapasitas mental dan perkembangan emosi konseli dalam memahami isi film, menangkap makna, serta mengenali persamaan dan perbedaan antara konseli dan karakter.

d. Dalampemilihanfilm, pertimbangkan isu-isu yang berkaitan dengan budaya, ras, etnis, status sosial, ekonomi dan gender.

e. Setelah mendapatkan data asesmen, konselor dapat menggunakan film yang sesuai, tepat dan cocok berdasarkan asesmen yang telah dilakukan.

2. Tahap Dua: Persiapan

a. Tontonlah terlebih dahulu film yang akan digunakan dalam terapi, 
agar konselor mengetahui dimana bagian-bagian penting dalam film yang dapat ditelaah nantinya. Selain itu, kebanyakan film memiliki adegan-adegan yang kurang pantas atau kurang penting seperti konten seksual. Pada saat inilah konselor dapat mempersiapkan untuk melakukan penanganan berupa mempercepat film agar adegan tidak terlihat, atau langsung melompati ke bagian selanjutnya.

b. Dapatkan persetujuan atau izin dari wali (sebaiknya tertulis) untuk menggunakan film pada konseli khususnya konseli yang masih anakanak dan remaja, karena terkadang setiap wali (orang tua) memiliki pandangan yang berbeda terhadap apa yang cocok untuk anak mereka.

c. Rencanakan penampilan dengan mempertimbangkan waktu, lokasi, siapa saja yang boleh ikut menonton, apakah semua bagian film akan ditampilkan atau hanya memerlukan beberapa scene saja, apakah membutuhkan persepsi dari konseli yang lain sehingga dalam bentuk kelompok akan lebih baik.

d. Meyakinkan konseli untuk siap mengikuti terapi dengan cara memberitahukan cinematherapy, menjelaskan mengenai cara kerja dan keuntungannya bagi konseli sehingga konseli nantinya dapat berpartisipasi hingga akhir.

3. Tahap Tiga: Implementasi

a. Tetapkan film.

b. Jadwalkan sesi di kemudian hari untuk proses menonton dalam terapi.

4. Tahap Empat: Mengelola Pengalaman

a. Setelah menonton film, konselor harus memproses reaksi konseli, yaitu dengan mendiskusikan kesan keseluruhan dari konseli terhadap film. Pada umumnya banyak orang yang menyenangi pembicaraan mengenai film, khususnya film yang memang menarik untuk dibicarakan, karena mereka dapat berbicara mengenai perasaan dan persepsi dari karakter dalam film. Melalui diskusi ini diharapkan dapat membantu menjembatani pertanyaan konselor mengenai perasaan dan persepsi mereka sendiri.

\section{MOTIVASI}

Robins \& Judge mendefinisikan motivasi sebagai proses yang menjelaskan intensitas, arah dan ketekunan seorang individu untuk mencapai tujuannya (Robins \& Judge, 1996). Sedangkan Yudhawati \& Haryanto mengartikan motivasi sebagai kekuatan (energi) seseorang yang dapat menimbulkan tingkat persistensi dan antusiasismenya dalam melaksanakan suatu kegiatan, baik yang bersumber dari dalam diri individu itu sendiri maupun dari luar individu (Yudhawati \& Haryanto, 2011). Faktor-faktor yang mempengaruhi motivasi menurut Uno, bahwa motivasi adalah dorongan internal (faktor dalam diri) dan eksternal (faktor luar diri) seseorang untuk mengadakan perubahan tingkah laku. (Uno, 2008).

Teori Penetapan Tujuan (Goal Setting Theory), Edwin Locke mengemukakan bahwa niat untuk mencapai sebuah tujuan merupakan sumber motivasi yang utama. Edwin Locke (Nana 2005) mengemukakan bahwa dalam penetapan tujuan memiliki empat macam mekanisme motivasional yaitu: tujuan-tujuan mengarahkan perhatian, tujuan-tujuan mengatur upaya, tujuan-tujuan meningkatkan persistensi, tujuan-tujuan menunjang strategi-strategi dan rencanarencana kegiatan (Yudhawati \& Haryanto, 2011).

\section{REMAJA}

Adolescence atau remaja berasal dari kata latin adolescere yang berarti "tumbuh" atau "menjadi orang dewasa" (Hurlock, 1980). Santrock menambahkan bahwa remaja diartikan sebagai masa perkembangan transisi antara masa anak dan masa dewasa yang mencakup perubahan biologis, kognitif, dan sosial-emosional (Santrock, 2003). 
Hurlock menyatakan bahwa masa remaja berlangsung sejak usia 13-18 tahun, yang terbagi atas masa remaja awal (13-17 tahun), dan masa remaja akhir (17-18 tahun).

Dokter telah menemukan cinematherapy menjadi sangat efektif dengan remaja, karena film adalah "media yang kuat dalam masyarakat kontemporer dan merupakan bagian sangat penting dari budaya remaja" (Hebert \& Neumeister, 2001). Film membantu remaja dalam membuat hubungan antara fantasi dalam kehidupan dan realitas saat ini (Chethik, 2000), dan memiliki pengaruh meyakinkan terhadap prasangka mereka tentang kehidupan (Wedding \& Niemiec). Pada saat mereka memperjuangkan tahapan perkembangan dengan penghargaan diri dan pembentukan identitas (Brinthaupt \& Lipka, 2002), remaja terhubung dengan kekuatan cinematherapy (Powell, 2006).

Di dalam proses aktif penayangan film atau sinema, terdapat proses kognisi saat menonton film sampai seseorang menemukan titik penemuan makna, yaitu: Logika (alur cerita), bahasa (dialog), visual spacial (gambar, warna simbol), musik (suara dan musik), interpersonal, kinestetik dan intrapsychic.

\section{METODOLOGI PENELITIAN}

Penelitian ini bertujuan

untuk mengetahui efektivitas layanan cinematherapy terhadap motivasi pada siswa SMA Negeri 59 Jakarta yang menjadi anggota kelompok. Penelitian dilaksanakan di SMA Negeri 59 Jakarta yang terletak di Jalan Bulak Timur I/ 10-11 Klender, Jakarta Timur yang dilakukan pada semester ganjil tahun ajaran 2015-2016 di bulan Juli sampai dengan September 2015. Metode penelitian yang digunakan adalah eksperimen. Jenis penelitian eksperimen yang dilakukan adalah Quasi Experimental Design dengan bentuk Nonequivalent Control Group Design. Desain ini sama seperti pretest-posttest control group design hanya saja sampel tidak dipilih secara random (Sugiyono, 2010). Kelompok eksperimen dan kelompok kontrol akan diberikan pretest. Selanjutnya, kelompok eksperimen diberikan perlakuan sedangkan kelompok kontrol tidak diberikan perlakuan. Kemudian kedua kelompok diberikan posttest.

Proses terapi ini dilakukan dalam waktu 30-90 menit dan peralatan yang dibutuhkan yaitu: laptop, LCD, film, ruangan/ tempat yang kondusif, kertas HVS dan alat tulis. Film yang digunakan merupakan jenis film cerita yang berjudul "Negeri 5 Menara". Prosedur penelitian dalam penelitian ini terdiri dari empat tahapan yaitu asesmen, persiapan, implementasi dan mengelola pengalaman yang telah disesuaikan dengan kebutuhan anggota kelompok. Populasi penelitian ini adalah siswa SMA Negeri 59 Jakarta kelas XI. Sampel terdiri dari 16 siswa berdasarkan hasil prestest dengan kategori motivasi belajar yang rendah. Pengelompokan data penelitian mengacu pada kriteria kategorisasi, dalam penelitian ini diberlakukan norma kategorisasi dengan kriteria: tinggi, sedang, dan rendah (Azwar, 2007).

Tabel 1

Kriteria Kategorisasi

\begin{tabular}{cc}
\hline Kategori & Kriteria Jenjang \\
\hline Tinggi & $198 \leq \mathrm{X} \leq 228$ \\
Sedang & $167 \leq \mathrm{X} \leq 197$ \\
Rendah & $135 \leq \mathrm{X} \leq 166$ \\
\hline
\end{tabular}

Instrumen penelitian ini menggunakan teori Motivasi dari Edwin Locke yang memiliki empat pilihan jawaban yaitu selalu (SL), sering (SR), jarang (JR), dan tidak pernah (TP) dengan skala Likert. Item uji coba 68 butir, item drop 5 butir dan item final 63 butir. Pengujian validitas menggunakan teknik Product Moment Pearson dan pengujian reliabilitas didapatkan hasil 0.940. menggunakan teknik Alpha Cronbach dengan bantuan aplikasi Statistical Product and Service Solution (SPSS) 17.0 for windows. Teknik analisis data 
yang digunakan dalam penelitian ini adalah Mann Whitney U-Test dengan menggunakan bantuan aplikasi Statistical Product and Service Solution (SPSS) 17.0 for Windows.

\section{HASIL DAN PEMBAHASAN}

Berdasarkan hasil pretest-posttest yang dilakukan pada kelompok eksperimen dan kelompok kontrol dengan masing-masing terdiri dari delapan siswa SMA Negeri 59 Jakarta didapatkan hasil sebagai berikut:

Tabel 2

\begin{tabular}{lccc}
\multicolumn{4}{c}{ Perbandingan Capaian Skor Per Dimensi } \\
\hline \multicolumn{1}{c}{ Dimensi } & $\begin{array}{c}\text { Skor } \\
\text { Pretest }\end{array}$ & $\begin{array}{c}\text { Skor } \\
\text { Posttest }\end{array}$ & $\begin{array}{c}\text { Gain } \\
\text { Skor }\end{array}$ \\
\hline $\begin{array}{l}\text { Tujuan-tujuan mengar- } \\
\text { ahkan perhatian }\end{array}$ & 587 & 696 & 109 \\
$\begin{array}{l}\text { Tujuan-tujuan menga- } \\
\text { tur upaya }\end{array}$ & 669 & 747 & 78 \\
$\begin{array}{l}\text { Tujuan-tujuan mening- } \\
\text { katkan persistensi }\end{array}$ & 491 & 613 & 122 \\
$\begin{array}{l}\text { Tujuan-tujuan yang } \\
\text { menunjang strate- } \\
\text { gi-strategi dan ren- } \\
\text { cana-rencana kegiatan }\end{array}$ & 700 & 776 & 76 \\
\hline
\end{tabular}

Tabel 3

Capaian Skor

\begin{tabular}{ccccc}
\hline $\begin{array}{c}\text { Rata-rata } \\
\text { Capaian Skor }\end{array}$ & $\begin{array}{c}\text { Skor } \\
\text { Ideal }\end{array}$ & Pretest & Posttest & $\begin{array}{c}\text { Peningka- } \\
\text { tan (\%) }\end{array}$ \\
\hline $\begin{array}{c}\text { Kelompok } \\
\text { Eksperimen }\end{array}$ & 252 & 148.6 & 188.8 & 15.92 \\
$\begin{array}{c}\text { Kelompok } \\
\text { Kontrol }\end{array}$ & 252 & 157.3 & 165.1 & 3.13 \\
\hline
\end{tabular}

Berdasarkan hasil pretest dan posttest pada dua kelompok terdapat perubahan skor yang terjadi. Pada kelompok eksperimen, sebelum diberikan perlakuan, seluruh anggota berada pada kategori rendah. Rata-rata skor sebelum diberi perlakuan sebesar 148.6. Sedangkan setelah diberikan perlakuan, ratarata skor meningkat sebesar 40.2 mencapai 188.8. Sedangkan pada kelompok kontrol, rata-rata skor sebelum perlakuan sebesar 157.3 dengan keseluruhan siswa berada pada kategori rendah. Kelompok kontrol ini tidak mendapatkan perlakukan seperti kelompok eksperimen, terdapat peningkatan skor sebesar 7.8 yaitu mencapai 165.1 pada kelompok ini.

Tabel 4

Data Capaian Skor Motivasi Belajar

\begin{tabular}{|c|c|c|c|c|c|}
\hline \multirow[b]{2}{*}{$\begin{array}{l}\text { त } \\
\frac{0}{0} \\
\frac{3}{0} \\
\frac{0}{\pi}\end{array}$} & \multirow[b]{2}{*}{$\begin{array}{l}\text { Skor } \\
\text { Ideal }\end{array}$} & \multirow[b]{2}{*}{ Nama } & \multicolumn{3}{|c|}{ SKOR } \\
\hline & & & $\begin{array}{c}\text { Pretest } \\
\%\end{array}$ & $\begin{array}{c}\text { Posttest } \\
\%\end{array}$ & 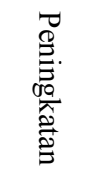 \\
\hline \multirow{8}{*}{$\begin{array}{l}\pi \\
\text { 吾 } \\
0\end{array}$} & \multirow{8}{*}{252} & AAP & 59.92 & 78.97 & 19.05 \\
\hline & & DMDW & 53.97 & 65.87 & 11.9 \\
\hline & & EMGW & 58.73 & 79.37 & 20.64 \\
\hline & & FARP & 65.08 & 77.38 & 12.3 \\
\hline & & MFI & 56.35 & 78.17 & 21.82 \\
\hline & & MRP & 53.57 & 67.46 & 13.89 \\
\hline & & MM & 61.11 & 71.03 & 9.92 \\
\hline & & WS & 63,1 & 80,95 & 17,85 \\
\hline \multirow[b]{2}{*}{$\begin{array}{l}\text { त } \\
\frac{\mathbb{0}}{\circ} \\
\frac{3}{0} \\
\frac{0}{\pi}\end{array}$} & \multirow[b]{2}{*}{$\begin{array}{l}\text { Skor } \\
\text { Ideal }\end{array}$} & \multirow[b]{2}{*}{ Nama } & \multicolumn{3}{|c|}{ SKOR } \\
\hline & & & $\begin{array}{c}\text { Pretest } \\
\%\end{array}$ & $\begin{array}{c}\text { Posttest } \\
\%\end{array}$ & 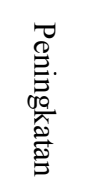 \\
\hline \multirow{8}{*}{$\begin{array}{l}\text { 조 } \\
\stackrel{0}{0} \\
0\end{array}$} & \multirow{8}{*}{252} & $\mathrm{AR}$ & 65.87 & 68.65 & 2.78 \\
\hline & & AA & 59.52 & 81.75 & 22.23 \\
\hline & & $\mathrm{AL}$ & 60.32 & 56.75 & -3.57 \\
\hline & & CCR & 65.87 & 69.05 & 3.18 \\
\hline & & HFW & 62.3 & 65.87 & 3.57 \\
\hline & & JLT & 63.49 & 56.75 & -6.74 \\
\hline & & LA & 56.75 & 60.71 & 3.96 \\
\hline & & ST & 65.08 & 64.68 & -0.4 \\
\hline
\end{tabular}

Terapi ini dilakukan dalam delapan sesi pertemuan sesuai dengan kebutuhan terapi. Persiapan pelaksanaan terapi dimulai dari pemberian pretest, pembentukan kelompok te rapi dan perencanaan jadwal pertemuan di setiap sesi terapi. Pada penelitian ini, terapi akan diberikan kepada delapan konseli pada kelompok eksperimen, yaitu AAP, DMDW, EMGW, FARP, MFI, MRP, MM dan WS. Pelaksanaan cinematherapy dilakukan dengan empat tahapan yaitu asesmen, persiapan, implementasi dan mengelola pengalaman. Tahap asesmen 
dilakukan sebagai pengumpulan data sehingga peneliti mengetahui lebih dekat pribadi konseli. Tahap persiapan, yaitu mempersiapkan segala keperluan yang akan digunakan dalam proses cinematherapy agar sesuai dengan kebutuhan anggota kelompok. Tahap implementasi, berlangsungnya proses cinematherapy dengan menonton film dimana para anggota kelompok mampu mengidentifikasi tokoh, mengalami katarsis emosi dari film yang ditayangkan. Pada tahap mengelola pengalaman, pada tahap ini dilakukan proses diskusi anggota kelompok untuk mengungkapkan segala perasaan yang dirasakan atau hal lain dalam sesi sebelumnya hingga tercapaikan makna dan terinspirasi dari film yang ditonton.

Berdasarkan hasil penghitungan dengan menggunakan SPSS, nilai Asymp. Sig sebesar 0.012 yang berarti nilai probabilitas lebih kecil dari nilai signifikansi $\alpha$ 0.05. Dengan demikian dapat disimpulkan bahwa $\mathrm{H}_{0}$ ditolak karena terbukti bahwa pemberian perlakuan cinematherapy dapat meningkatkan motivasi dan $\mathrm{H}_{1}$ diterima, yaitu terjadi peningkatan motivasi yang tinggi setelah diberikan perlakuan. Maka dapat disimpulkan bahwa, terdapat pengaruh cinematherapy terhadap peningkatan motivasi siswa SMA Negeri 59 Jakarta.

Proses yang terjadi dalam menonton film dapat diketahui dengan memahami alur cerita dan karakter tokoh dalam sebuah film, menimbulkan kerja aktif dalam otak yang menunjukkan isu-isu motivasi terhadap emosi diri sehingga membangkitkan alam bawah sadar seseorang. Luapan emosi yang terjadi membawa penonton seolaholah berada dalam alur cerita film tersebut. Seseorang akan merasa mengalami sendiri apa yang dirasakan tokoh-tokoh dalam cerita dengan penggunaan simbol-simbol yang menjadi dasar sugesti oleh indra penglihatan yang memaknai arti dari simbol atau gambar. Kemudian alam bawah sadar mencoba mengkomunikasikan dengan alam sadar melalui imajinasi. Hingga titik akhir adalah menemukan maksud dari alur cerita film. Penemuan maksud dari film ini dapat menginspirasi seseorang yang kemudian mendorong seseorang untuk memotivasi dirinya selama proses penayangan film.

Keterbatasan penelitian yang dialami oleh peneliti diantaranya yaitu: (1) Tidak semua anggota memiliki kegemaran menonton film dengan tema tertentu karena sampel yang dipilih hanya berdasarkan kategori motivasi rendah. (2) Waktu yang diberikan pihak sekolah terbatas sehingga pada sesi menonton film terpotong karena terbentur dengan jam pelajaran siswa selanjutnya yang dikhawatirkan akan mengganggu belajarnya dan membuat siswa kurang fokus. (3) Hasil penelitian ini hanya berlaku pada kelompok penelitian dengan situasi yang tercipta saat kegiatan berlangsung, tidak dapat digeneralisasikan kepada kelompok dan situasi lain. (4) Proses pelaksanaan cinematherapy yang dirasakan masih banyak kekurangan karena peneliti merupakan pemula dan sumber-sumber yang cukup sulit dicari. (5) Terdapat faktor internal dan eksternal pada motivasi dari responden yang tidak dapat dikendalikan oleh peneliti saat dilakukannya penelitian sehingga mempengaruhi proses terapi dan hasil posttest penelitian.

\section{KESIMPULAN DAN SARAN}

Cinematherapy dapat digunakan untuk membantu siswa meningkatkan motivasinya. Siswa dengan permasalahan motivasi meningkat pada keempat skor dimensitujuan-tujuanmengarahkan perhatian, tujuan-tujuan mengatur upaya, tujuan-tujuan meningkatkan persistensi, tujuan-tujuan menunjang strategi-strategi dan rencanarencana kegiatan. Skor menunjukkan bahwa siswa telah mampu dalam meningkatkan fokus dan mampu mengatur strategi serta rencana dalam mencapai apa yang menjadi target tujuannya.

Berdasarkan hasil uji hipotesis dengan menggunakan teknik Mann Whitney $U$ Test, diperoleh nilai Asymp. Sig sebesar 0.012 yang berarti lebih kecil dari nilai signifikansi $\alpha$ 0.05. Hal ini berarti $\mathrm{H}_{0}$ ditolak dan $\mathrm{H}_{1}$ 
diterima, yaitu terjadinya peningkatan skor motivasi setelah diberikan perlakuan berupa cinematherapy atau terapi film. Disimpulkan bahwa film dapat digunakan untuk membantu meningkatkan motivasi siswa.

Berdasarkan hasil penelitian, saransaran yang dapat dipertimbangkan yaitu: bagi mahasiswa Bimbingan dan Konseling yang akan melakukan penelitian serupa perlu melakukan penyempurnaan terutama pada tahap persiapan dan proses pelaksanaan, bagi guru Bimbingan dan Konseling yaitu membuat atau memperbaiki program yang berhubungan dengan strategi untuk mengatasi masalah motivasi pada siswa, dan bagi kepala sekolah yaitu mengoptimalkan sarana dan prasarana di sekolah dalam pelaksanaan cinematherapy.

\section{DAFTAR PUSTAKA}

Arends, R. (2008). Learning To Teach Belajar Untuk Mengajar (7th ed.). Yogyakarta: Pustaka Pelajar.

Azwar, S. (2007). Penyusunan Skala Psikologi. Yogyakarta: Pustaka Pelajar.

Demir, E.S. (2007). Cinema Therapy. Metu: State University Of Metu.

Locke \& Latham. (2006). New Directions in Goal-Setting Theory. Association for Psychological Science, 15(5), 265-268.

Morgan. (1986). Introduction to Psychology (7th ed.). Singapore: McGraw Hill Book.

Powell, M. L. (2006). Group cinematherapy: Using Metaphor To Enhance Adolescent Self Esteem. Vayetteville: University of Arkansas.

Robbins, \& Judge. (1996). Organizational Behaviour (7th ed.). New Jersey: Prentice Hall.

Sugiyono. (2010). Metode Penelitian Pendidikan: Pendekatan Kuantitatif, Kualitatif dan $R \& D$. Alfabeta: Bandung.

Uno, H. B. Teori Motivasi dan Pengukurannya Analisis di Bidang Pendidikan. Jakarta: Bumi Aksara.

Wolz, B. (2003). Cinematherapy: using the power of image in film for the therapeutic process. The Therapist.

Yang, H. (2005). The use of single-session cinematherapy and aggressive behavioral tendencies among adopted
children-A pilot study. Corbondale: Southern Illinois University.

Yosep, I. (2008). Keperawatan Jiwa. Bandung: Refika Aditama.

Yudhawati \& Haryanto. (2011). Teori-Teori Dasar Psikologi Pendidikan. Jakarta: Prestasi Pustakarya. 